\title{
Investigation of Carbon-Based Composites for Elastic Heaters and Effects of Hot Pressing in Thermal Transfer Process on Thermal and Electrical Properties
}

\author{
Tomasz Raczyński ${ }^{1,2, *}$, Daniel Janczak ${ }^{1,2}$, Jerzy Szałapak ${ }^{1,2}$, Piotr Walter ${ }^{1,2}$ and Małgorzata Jakubowska ${ }^{1,2}$ \\ 1 Institute of Metrology and Biomedical Engineering, Faculty of Mechatronics, Warsaw University of \\ Technology, 00-661 Warsaw, Poland; daniel.janczak@pw.edu.pl (D.J.); jerzy.szalapak@pw.edu.pl (J.S.); \\ piotr.walter.dokt@pw.edu.pl (P.W.); malgorzata.jakubowska@pw.edu.pl (M.J.) \\ 2 Central Laboratory, Centre for Advanced Materials and Technologies (CEZAMAT), 02-822 Warsaw, Poland \\ * Correspondence: tomasz.raczynski.dokt@pw.edu.pl
}

check for

updates

Citation: Raczyński, T.; Janczak, D.; Szałapak, J.; Walter, P.; Jakubowska, M. Investigation of Carbon-Based Composites for Elastic Heaters and Effects of Hot Pressing in Thermal Transfer Process on Thermal and Electrical Properties. Materials 2021 14, 7606. https://doi.org/10.3390/ ma14247606

Academic Editor: Shih-Chen Shi

Received: 20 October 2021

Accepted: 6 December 2021

Published: 10 December 2021

Publisher's Note: MDPI stays neutral with regard to jurisdictional claims in published maps and institutional affiliations.

Copyright: (c) 2021 by the authors. Licensee MDPI, Basel, Switzerland. This article is an open access article distributed under the terms and conditions of the Creative Commons Attribution (CC BY) license (https:/ / creativecommons.org/licenses/by/ $4.0 /)$.

\begin{abstract}
Wearable electronics are new structures with a wide range of possible applications. This study aims to analyze the effects of hot pressing in thermal transfer of different carbon-based composites as a new application method of screen-printed electronics on textiles. Flexible heaters were screen-printed on polyethylene terephthalate PET foil with composites based on graphene, carbon black, and graphite with different wt.\%, measured and then hot pressed to measure and analyze differences. Research showed that the hot pressing process in thermal transfer resulted in decreased electrical resistance, increased power, and higher maximal temperatures. Best results were achieved with composites based on $12 \mathrm{wt}$.\% graphene with sheet resistance lowered by about $40 \%$ and increased power by about $110 \%$. This study shows promise for thermal transfer and screen-printing combination as an alternative for creating flexible electronics on textiles.
\end{abstract}

Keywords: wearable electronics; printed electronics; thermal transfer; carbon elastic heaters; screen-printing

\section{Introduction}

Driven by marketing, trends among the youth, and high capital, wearable electronics are becoming one of the most popular and highly discussed topics [1]. Many companies are already in this market, offering smartwatches, pulsometers, smart bands, and other smart accessories. Offered products already evolved beyond medical purposes, entering a sphere of commercial, entertainment, or industrial applications [2].

With an increase in demand, research and development of those technologies became more focused. The development of digital medicine was one of the most important driving factors behind this change. Due to a need to monitor patients over prolonged periods and sometimes even do it remotely [3], wearable electronics moved from carried elements to integrated electronics. However, this transition comes with its difficulties. Those new devices must be flexible, convenient to use, miniaturized, and even aesthetically appealing.

The niche thus created has been filled by thick-film electronics. Screen printing is an example of the implementation of this technology. It allows flexibility in designing patterns and using different materials while maintaining mechanical strength without sacrificing electrical performance, dimensions, and convenience [4]. However, direct printing on fabric comes with its own set of complications. The un-uniformity and pliability of substrate hinders the printing process at the cost of repeatability and the ability to print small-sized structures. Indirect printing, in which the printing process is separated from transferring the print to the fabric, might solve this problem, allowing for increased accuracy and repeatability. However, this is a little researched method that is still in the development phase.

In the present paper, the authors focused on flexible heaters as a potential application for flexible electronics. Currently, there is an increasing demand for flexible heaters. They 
are used in the semiconductor industry [5] as portable heaters for personal use [6] or for reheating food [7]. They work as resistance heaters, which allows for precise temperature control by changing the voltage. Classically used heaters are made of rare materials or lack the flexibility needed for more demanding applications [8].

For this reason, composite solutions containing nanomaterials are being explored. It allows the use of flexible substrates and vehicles while maintaining low resistance. The primary materials chosen are silver nanowires or carbon-based nanomaterials. Currently researched materials and methods are presented in Table 1 . The use of silver nanomaterials results in low resistances, but carbon-based materials permit the production of biodegradable components and lower production costs. The method of laser pattering resulted in high temperatures, but such a process is slow and costly, not allowing for mass production. Of all those methods, screen printing allows for the most effortless mass production of such heaters. The main parameter of electric heaters is resistance. Change of this parameter during the design process allows for direct control of the power of a heater. Based on the available literature, heaters resistance should be under $1000 \Omega$ /sq.

However, to manufacture such wearable electronics in industrial quantities, it is necessary to simplify the process and ensure repeatability. This can be achieved by using a combination of screen printing and thermal transfer. Directly screen-printing electrical structures on textiles comes with many different complications. The elasticity of textiles as a substrate makes it difficult to position for multi-layered structures, and high permeability makes it impossible to mount using a vacuum table commonly used in the screen-printing process. Thermal transfer separates the process of printing the electronics from applying them to the fabric, allowing the use of less complicated equipment and the exploitation of existing processes. The use of thermal transfer in creating flexible electronics on fabrics is a very new field. Currently, printing conductive surfaces using ink containing silver nanowires [9], a body heat absorber integrated into clothing [10], an antenna for signal transmission made of carbon inks [11], and a piano integrated into fabric [12] have been investigated. Due to the novelty of this technology and its potential for mass production, it requires further investigation.

Table 1. Comparison of Materials, Production Methods, Electrical and Thermal Properties of Existing Research into Flexible Heaters.

\begin{tabular}{|c|c|c|c|c|c|}
\hline Material & Production Method & Resistance, $\Omega /$ sq. & Voltage, V & Temperature, ${ }^{\circ} \mathrm{C}$ & Source \\
\hline Graphene Oxide & Laser patterning & 1000 & 18 & 247.3 & [13] \\
\hline $\begin{array}{c}\text { Graphene Oxide, silver } \\
\text { particles }\end{array}$ & Drop coating & 158 & 15 & 160 & [14] \\
\hline $\begin{array}{l}\text { Single-walled carbon } \\
\text { nanotubes }\end{array}$ & Doctor-blade & 93 & 7 & 140 & [15] \\
\hline Silver nanowire & Polymer casting & 30 & 10 & 200 & [6] \\
\hline Silver nanowire & Polymer casting & 30 & 16 & 131 & [16] \\
\hline Silver nanowire & Screen-printing & 380 & 40 & 99 & [8] \\
\hline Silver fractal dendrites & Screen-printing & 0.83 & 2 & 107.4 & [17] \\
\hline Graphene, carbon nanotubes & $\begin{array}{l}\text { Screen-printing and } \\
\text { lamination }\end{array}$ & 500 & 12 & 57 & [18] \\
\hline
\end{tabular}

This work investigates different carbon-based composites for flexible heaters and the effects of hot pressing in the thermal transfer on their thermal and electrical properties. The results of this study will help to understand the process of thermal transfer better and help to facilitate further research in textile integrated electronics.

\section{Materials and Methods}

\subsection{Materials}

Three types of material were chosen for conductive components of produced composites. Graphene nanoplatelets type C (GNP C), acquired commercially from CheapTubes, Grafton, MA, USA, was chosen based on previous research [19-21]. Following successful 
results in conductive composites research [22-25], conductive soot, purchased as Carbon Black (CB) from Graphene Laboratories Inc., Calverton, NY, USA, was chosen. The last tested material was graphite, proven for its conductivity [26-28] and purchased as MG 1596 from Termoplastik, Bydgoszcz, Poland. Different physical properties of those materials: dimensions and volume, are presented in Table 2.

Table 2. Physical Properties of Chosen Carbon Materials.

\begin{tabular}{cccc}
\hline Material & Diameter, $\boldsymbol{\mu \mathbf { m }}$ & Thickness, $\mathbf{n m}$ & Surface Area, $\mathbf{~}^{\mathbf{2}} / \mathbf{g}$ \\
\hline GNP C & 2 & $8-15$ & $500-700$ \\
CB & 0.3 & 30 & 254 \\
Graphite & 10 & 10,000 & $\sim 1.5$ \\
\hline
\end{tabular}

To produce the organic base for flexible heaters, thermoplastic polyurethane polymer (TPU) was chosen. It was characterized by 37 Shore hardness, the density of $1.18 \mathrm{~g} / \mathrm{cm}^{3}$, shear resistance of $27 \mathrm{~N} / \mathrm{mm}$, the tensile strength of $12 \mathrm{MPa}$, and elongation before breaking of $1150 \%$. It was commercially acquired from the BASF company. It was used as a solution in a mixture of Dimethylformamide (DMF).

All structures were printed on PET foil with a thickness of $125 \mu \mathrm{m}$.

\subsection{Preparations}

To produce the vehicle for carbon-based composite, a solution containing $20 \mathrm{wt} . \%$ of TPU in DMF was prepared to ensure rheological properties appropriate for screen printing [4]. The dissolution process was conducted at a temperature of $30^{\circ} \mathrm{C}$ using a magnetic mixer for two hours.

Carbon materials in desired amounts were mixed with a vehicle in a speed mixer until achieving a homogenous composite. Composites were prepared using GNP C (10-20 wt.\%), CB (10-17 wt.\%), and Graphite (20-40 wt.\%). Amounts of the carbon material were chosen to achieve the highest density of carbon materials with rheological properties still suitable for screen printing.

Composites were screen printed using $68 \mathrm{~T}$ polyester mesh creating $10 \times 28 \mathrm{~mm}$ heaters, dried for $20 \mathrm{~min}$ at $120^{\circ} \mathrm{C}$. Samples were then measured, hot pressed, and then measured again. They were pressed using a heat press with a temperature of $180^{\circ} \mathrm{C}$ for $60 \mathrm{~s}$ with a force of $150 \mathrm{~g} / \mathrm{cm}^{2}$. The schematic of this process is shown in Figure 1.
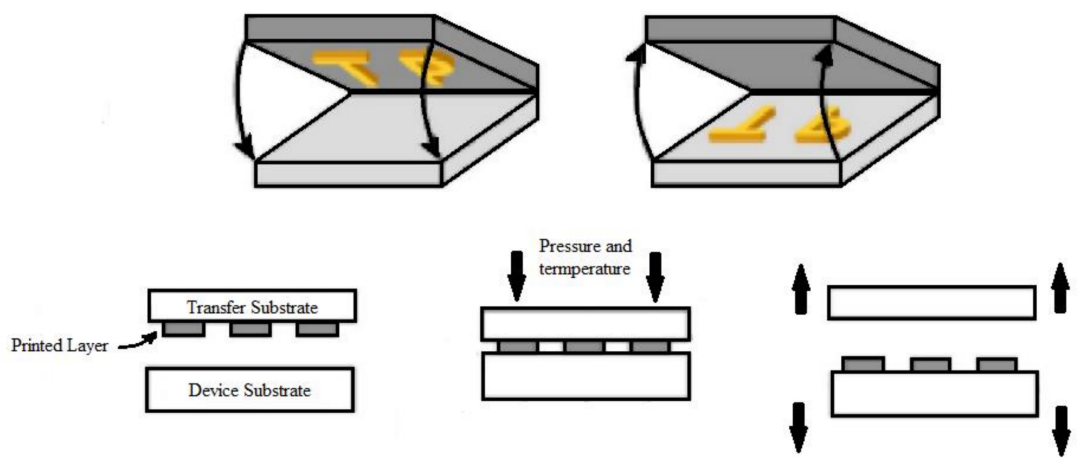

Figure 1. Schematic of the thermal transfer process.

\section{Results and Discussion}

To check the viability of prepared composites for screen printing, their rheological properties were measured. They were tested using the cone-plate method with an increasing shear rate. Results of those measurements are displayed in Figure 2. The viscosity of prepared pastes was increasing with higher wt. $\%$ of active phase as expected. Due to the high viscosity of composites containing $18 \mathrm{wt} . \%$ and $20 \mathrm{wt} . \%$ graphene those were not possible to screen-print. 


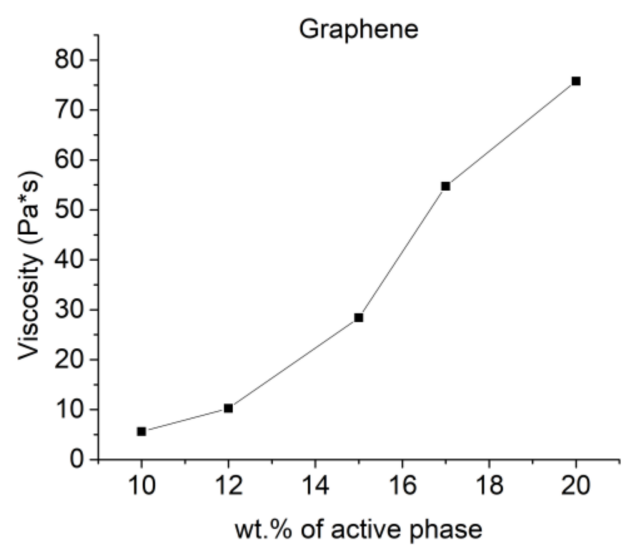

(a)

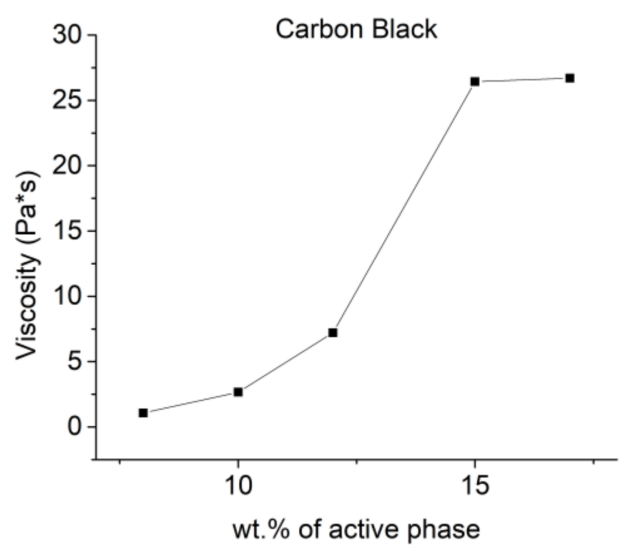

(b)

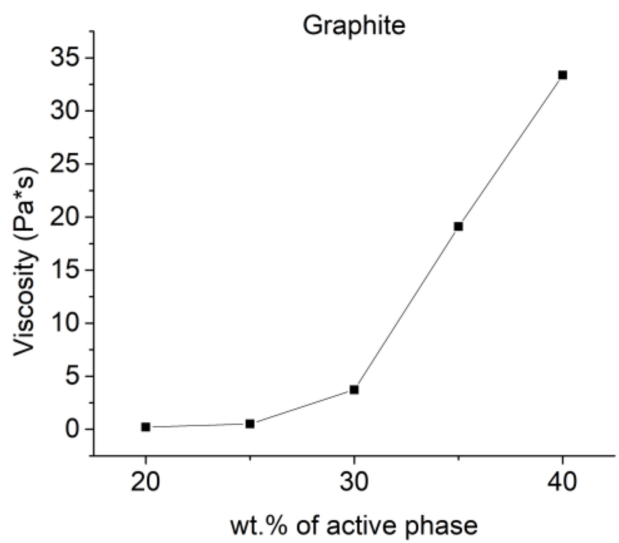

(c)

Figure 2. Rheological measurements of prepared composites displaying the relationship between wt.\% of active phase and viscosity with the shear rate of 50 1/s for composites based on: (a) Graphene; (b) Carbon black; (c) Graphite.

After successful screen-printing, the resistance of all heaters $(n=20)$ was measured. Next, they were hot-pressed and measured again. Results of those measurements are presented in Table 3, with additional comparisons of results before and after the hot pressing process in Figure 3.

Table 3. Detailed Results of Resistance Measurements Before and After a Hot Pressing Process for Heaters Screen-Printed with Different Composites.

\begin{tabular}{ccc}
\hline Sample Name & $\begin{array}{c}\text { Resistance Before Hot } \\
\text { Pressing, } \mathbf{k} \Omega / \mathbf{s q} .\end{array}$ & $\begin{array}{c}\text { Resistance After Hot } \\
\text { Pressing, } \mathbf{\Omega} / \mathbf{s q} .\end{array}$ \\
\hline GNPC_10 & $1.80 \pm 0.4085$ & $1.59 \pm 0.13608$ \\
GNPC_12 & $1.38 \pm 0.48518$ & $0.84 \pm 0.31876$ \\
GNPC_15 & $1.10 \pm 0.31062$ & $1.17 \pm 0.31077$ \\
CB_10 & $3.08 \pm 0.12073$ & $3.22 \pm 0.38048$ \\
CB_12 & $2.48 \pm 0.23937$ & $2.33 \pm 0.2547$ \\
CB_15 & $1.64 \pm 0.23031$ & $1.68 \pm 0.22878$ \\
CB_17 & $1.73 \pm 0.23592$ & $1.61 \pm 0.25223$ \\
G_20 & $9.87 \pm 1.33997$ & $9.05 \pm 1.87091$ \\
G_25 & $7.56 \pm 1.45489$ & $7.37 \pm 1.61598$ \\
G_30 & $2.48 \pm 0.48055$ & $2.24 \pm 0.23633$ \\
G_35 & $2.36 \pm 1.37034$ & $2.16 \pm 1.21135$ \\
G_40 & $1.42 \pm 0.43242$ & $1.36 \pm 0.19569$ \\
\hline
\end{tabular}




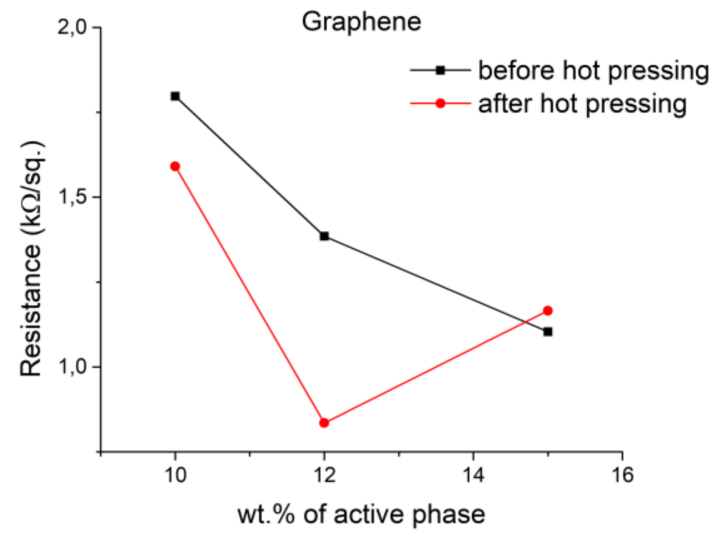

(a)

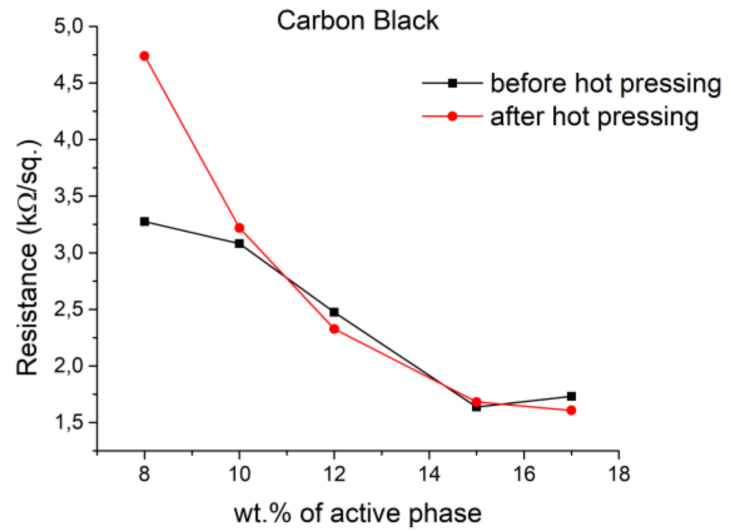

(b)

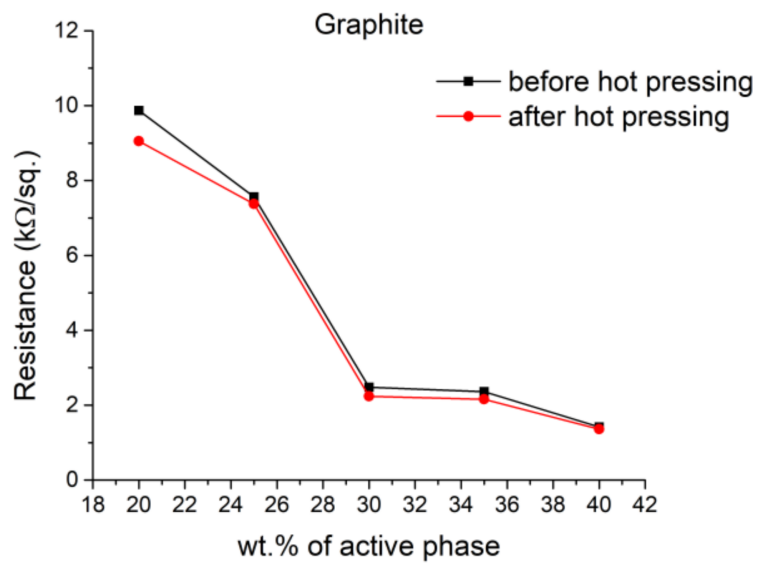

(c)

Figure 3. Comparison of resistances before and after a hot pressing process for heaters screen-printed with different compositions of pastes based on: (a) Graphene; (b) Carbon black; (c) Graphite.

While heaters made using graphite and carbon show no changes, those made with graphene display lower resistances after hot pressing, decreasing their value by about $40 \%$. The high surface area of graphene should allow for the additional compression of composite, increasing numbers of connections between single platelets and thus resulting in lower electrical resistance. Janczak et al. [12] observed such phenomena, but with no change of resistance for carbon black, which also has a high surface area, such change in resistance comes from the shape of individual particles of conductive phase. While carbon black and graphite could be categorized as amorphic, graphene is in the shapes of platelets. During high pressure and temperature, TPU becomes malleable, allowing for a change of orientation of graphene nanoplatelets, positioning them in sheets, and lowering their resistance. Those changes are not visible in composites with $15 \mathrm{wt} . \%$ of graphene. This is due to the maximum filling threshold of graphene in composite, not allowing for compression on change in orientation. Using TPU and a combination of increased pressure and temperatures, those changes in the orientation of graphene will be persistent between thermal expansion and compression cycles of heaters. 
To test the proof of concept, a heater based on $12 \mathrm{wt} . \%$ graphene paste was connected to the power supply and measured with a Flir E5 thermal camera with a measuring range of $0-200{ }^{\circ} \mathrm{C}$ (Figure 4 ).

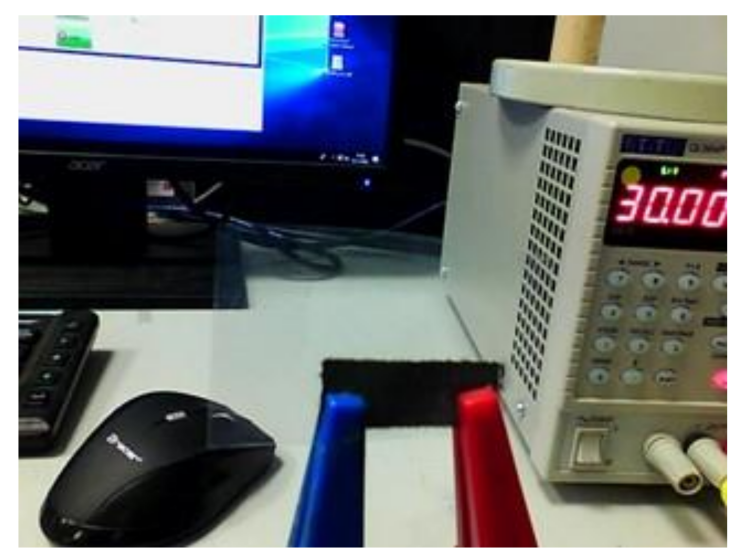

(a)

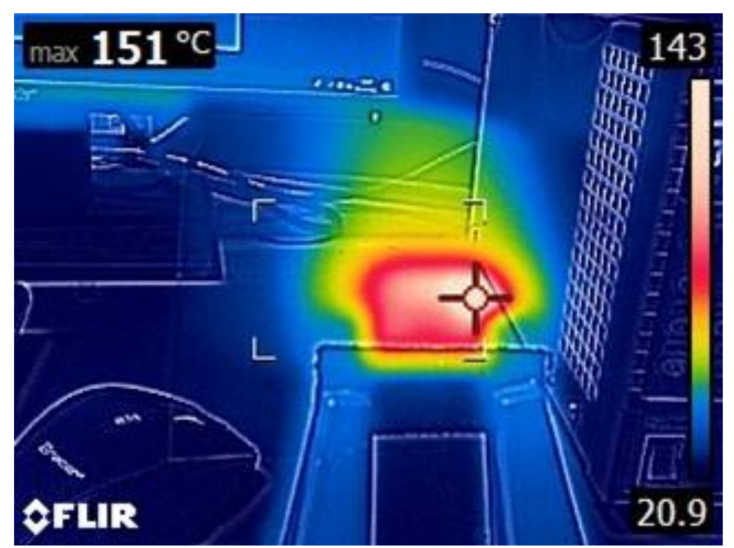

(b)

Figure 4. Photos showing measurement of heater screen-printed with $12 \mathrm{wt}$ \% graphene paste taken with a thermal camera: (a) regular picture, (b) thermal picture.

To evaluate the thermal properties of created heaters, they were connected to a power supply with a voltage value of $40 \mathrm{~V}$. During this measurement, resistance, power, and temperature were collected in relation to time. It allowed to discern multiple characteristics: heaters power, highest achieved temperature and heating speed. Results of those findings are displayed in Figure 5.

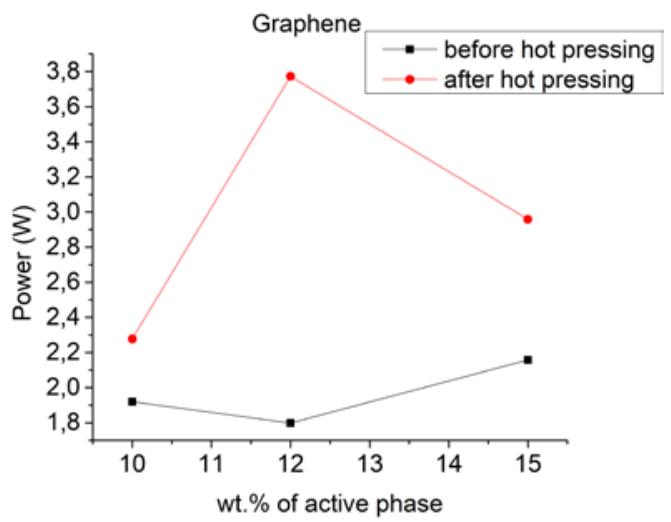

(a)

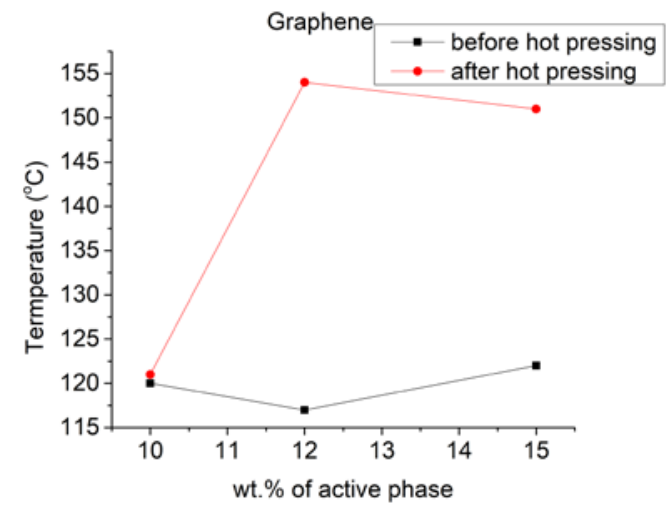

(b)

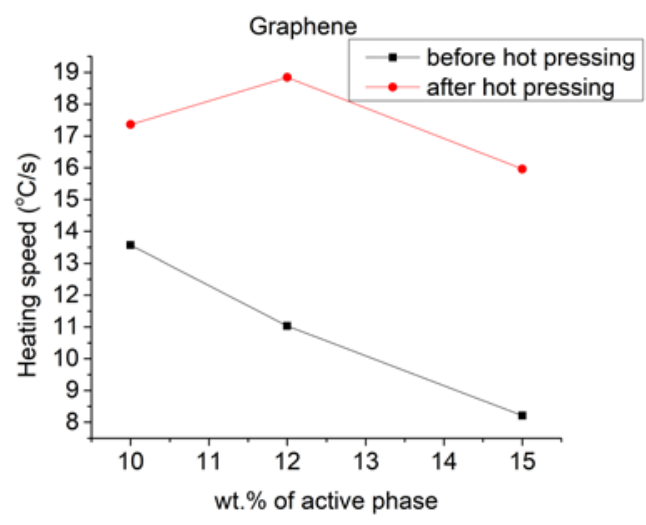

(c)

Figure 5. Cont. 


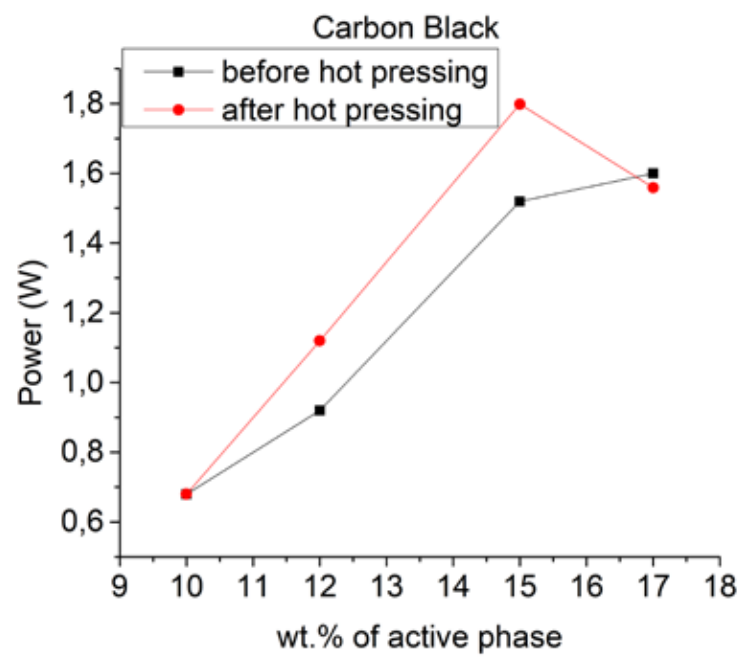

(d)

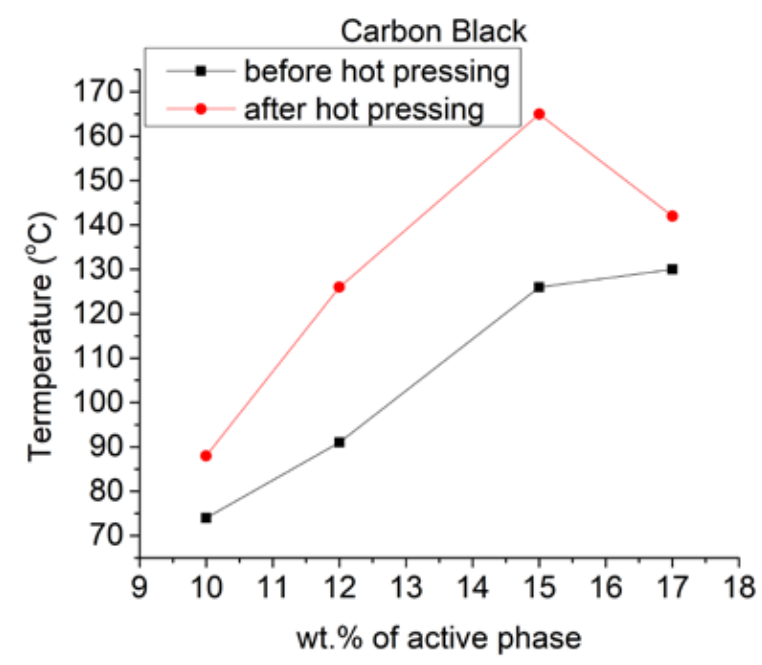

(e)

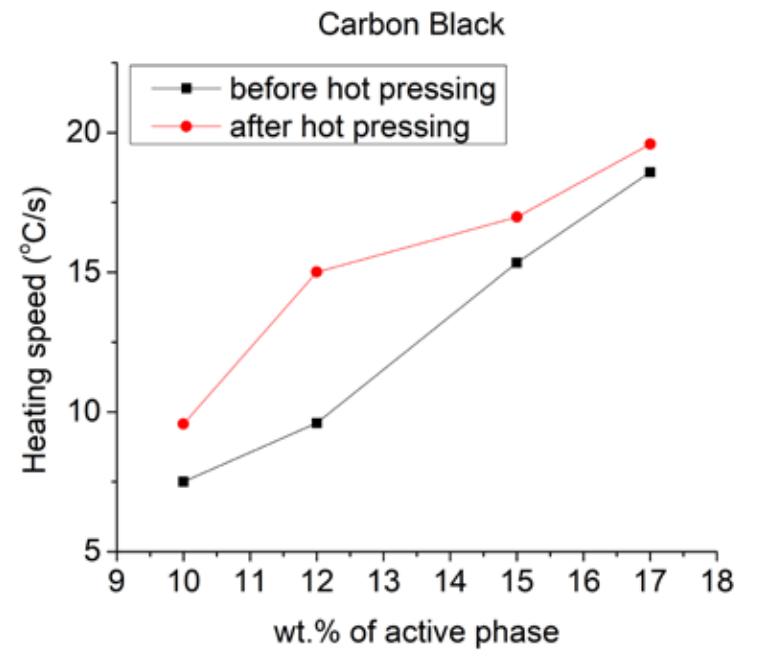

(f)

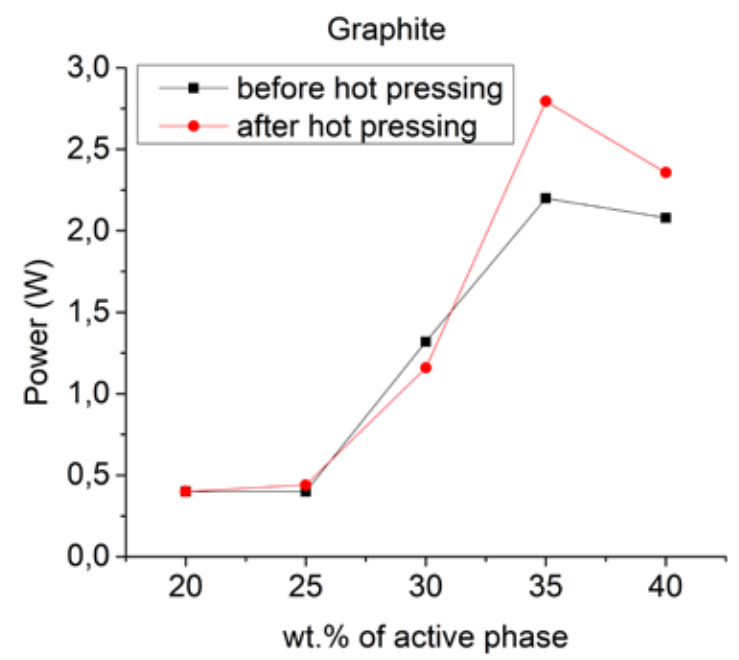

(g)

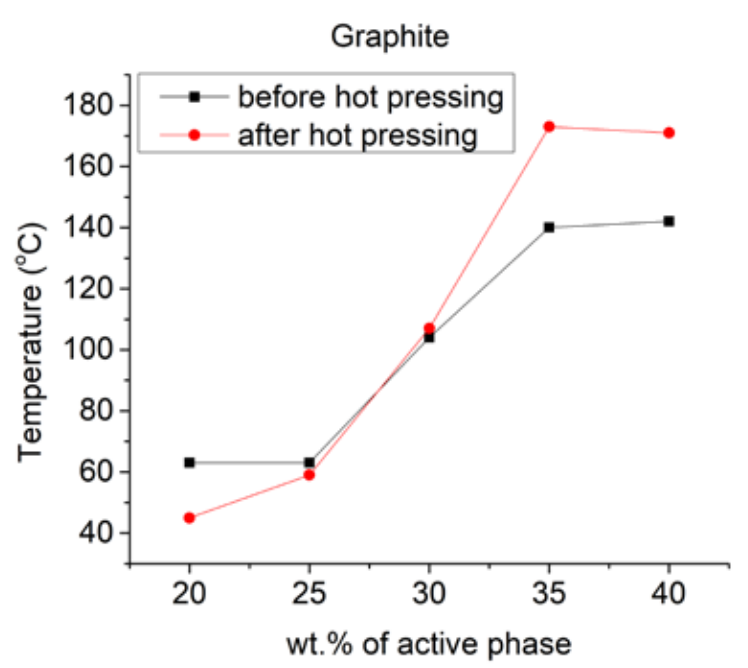

(h)

Figure 5. Cont. 


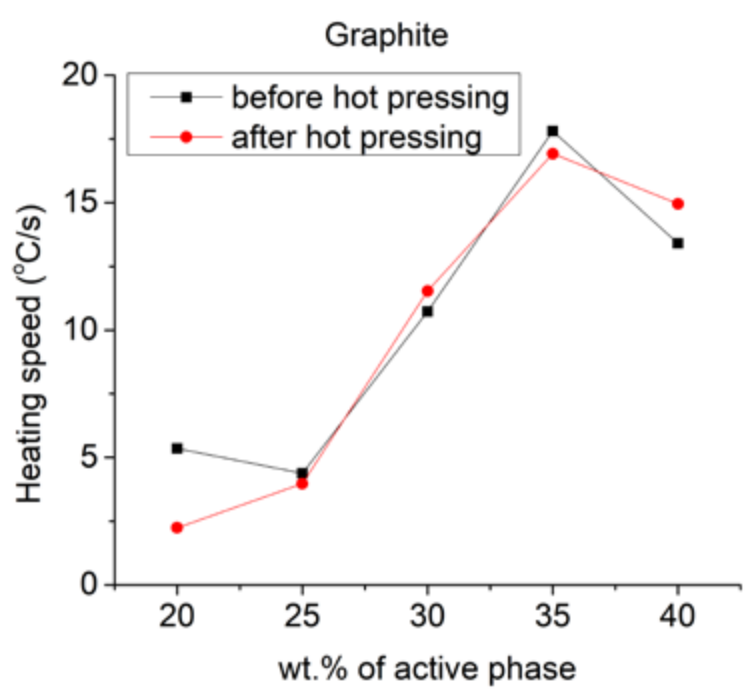

(i)

Figure 5. Results of evaluation of thermal properties of heaters made (a-c) with graphene nanoplatelets, (d-f) carbon black and (g-i) graphite showing the relation between wt.\% of functional phase and: $(\mathbf{a}, \mathbf{d}, \mathbf{g})$ power; $(\mathbf{b}, \mathbf{e}, \mathbf{h})$ resulting temperatures; $(\mathbf{c}, \mathbf{f}, \mathbf{i})$ heating speed; before and after hot pressing with an applied voltage of $40 \mathrm{~V}$.

From those results, the most noticeable changes were for heaters made with graphene. The best results were obtained for composites containing $12 \mathrm{wt} . \%$ graphene with an increase in power of around $110 \%$. Noteworthy was an increase in highest temperatures for $12 \mathrm{wt} . \%$ and $15 \mathrm{wt} . \%$ with differences up to $60^{\circ} \mathrm{C}$ and a constant increase in heating speed for all values resulting in more efficient and more dynamic heaters. As previously stated, such changes are an effect of the very high surface area of graphene nanoplatelets, that after compression increase in density, an increasing number of electrical connections between single platelets. Carbon black-based heaters showed a slight increase in power and heating speed with a more significant change of the highest temperature of about $40^{\circ} \mathrm{C}$ with almost no changes in electrical resistance. Heaters containing graphite showed a slight increase in power and highest temperatures for $35 \mathrm{wt} . \%$ and $40 \mathrm{wt} . \%$ with no noticeable heating speed changes. For carbon black and graphite, an increase in temperature can be attributed to increased density of composite after hot pressing, and lack of change in electrical resistance is mainly due to being unable to reach lower resistance values for this type of materials.

\section{Conclusions}

TPU based composites using graphene nanoplatelets, carbon black, and graphite were prepared. The rheological properties of those composites were measured to ascertain suitability for screen-printing. Heating structures were screen-printed using chosen pastes. A series of tests were made before and after the hot-pressing process to measure changes in resistance, power, temperature, and heating speed.

Of all tested materials, the best results were achieved using composites containing $12 \mathrm{wt} . \%$ graphene nanoplatelets. There was a decrease of sheet resistance of around $40 \%$ and an increase in power from $1.798 \mathrm{~W}$ to $3.773 \mathrm{~W}$. An increase in heating speed was also observed.

Performed tests showed that heat pressing in the thermal transfer process could improve screen-printed heaters' electrical and thermal properties. Conducted research shows that screen-printing and thermal transfer, due to its low production costs and results comparable to existing research, can have a high potential for applications in textronics. In addition, there is a possibility that the process of heat pressing can improve the electrical properties of other screen-printed composites. 
Author Contributions: Conceptualization, T.R. and D.J.; methodology, T.R. and D.J.; validation, D.J., M.J. and J.S.; formal analysis, T.R.; investigation, T.R and P.W.; data curation, T.R. and J.S.; writing-original draft preparation, T.R.; writing-review and editing, J.S. and P.W.; supervision, D.J.; project administration, M.J.; funding acquisition, M.J. All authors have read and agreed to the published version of the manuscript.

Funding: This research was funded by Statutory funds of the Institute of Metrology and Biomedical Engineering (Faculty of Mechatronics at the Warsaw University of Technology).

Institutional Review Board Statement: Not applicable.

Informed Consent Statement: Not applicable.

Data Availability Statement: All the data is available within the manuscript.

Conflicts of Interest: The authors declare no conflict of interest. The funders had no role in the design of the study; in the collection, analyses, or interpretation of data; in the writing of the manuscript, or in the decision to publish the results.

\section{References}

1. Matthew, R.; Dutta, J.; Maheswar, R.; Ahmed, K. Intelligent Wearable Electronics: A New Paradigm in Smart Electronics. In Challenges and Solutions for Sustainable Smart City Development EAI/Springer Innovations in Communication and Computing; Springer Nature: Cham, Switzerland, 2021; pp. 169-197. [CrossRef]

2. Hayward, J. Wearable Technology Forecasts 2019-2029; Report for IDTechEx; IDTechEx: 2019. Available online: https:/ /www. idtechex.com/en/research-report/wearable-technology-forecasts-2019-2029/680 (accessed on 18 December 2020).

3. Elenko, E.; Underwood, L.; Zohar, D. Defining Digital Medicine. Nat. Biotechnol. 2015, 33, 456-461. [CrossRef]

4. Janczak, D.; Zych, M.; Raczyński, T.; Dybowska-Sarapuk, Ł.; Pepłowski, A.; Krzemiński, J.; Sosna-Glłębska, A.; Znajdek, K.; Sibiński, M.; Jakubowska, M. Stretchable and Washable Electroluminescent Display Screen-printed on Textile. Nanomaterials 2019, 9, 1276. [CrossRef] [PubMed]

5. Cho, N.-I.; Kim, M.C. Preparation of Cr-Si Multilayer Structures for Thin Film Heater Applications. Thin Solid Films 2005, 475, 235-238. [CrossRef]

6. Hong, S.; Lee, H.; Lee, J.; Kwon, J.; Han, S.; Suh, Y.D.; Cho, H.; Shin, J.; Yeo, J.; Ko, S.H. Highly Stretchable and Transparent Metal Nanowire Heater for Wearable Electronics Applications. Adv. Mater. 2015, 27, 4744-4751. [CrossRef]

7. Shin, K.Y.; Hong, J.Y.; Lee, S.; Jang, J. High Electrothermal Performance of Expanded Graphite Nanoplatelet-based Patch Heater. J. Mater. Chem. 2012, 22, 23404-23410. [CrossRef]

8. He, X.; He, R.; Lan, Q.; Wu, W.; Duan, F.; Xiao, J.; Zhang, M.; Zeng, Q.; Wu, J.; Liu, J. Screen-Printed Fabrication of PEDOT:PSS/Silver Nanowire Composite Films for Transparent Heaters. Materials 2017, 10, 220. [CrossRef]

9. Maheshwari, N.; Abd-Ellah, M.; Goldthorpe, I.A. Transfer Printing of Silver Nanowire Conductive Ink for e-textile Applications. Flex. Print. Electron. 2019, 4, 025005. [CrossRef]

10. Elmoughni, H.M.; Menon, A.K.; Wolfe, R.M.W.; Yee, S.K. A Textile-Integrated Polymer Thermoelectric Generator for Body Heat Harvesting. Adv. Mater. Technol. 2019, 4, 10800708. [CrossRef]

11. Pulanthran, K.; Jizat, N.M.; Islam, M.S. A Low-cost Textile Antenna using Thermal-transfer Printing. In Proceedings of the 16th IEEE International Colloquium on Signal Processing and its Applications, CSPA 2020, Langkawi, Malaysia, 28-29 February 2020; pp. 162-165. [CrossRef]

12. Kost, L.; Pavec, M.; Michal, D.; Moravcova, D.; Soukup, R.; Hamacek, A. E-textile Piano Fabricated using Several Textile Technologies. In Proceedings of the International Spring Seminar on Electronics Technology, Demanovska Valley, Slovakia, 14-15 May 2020; pp. 1-5. [CrossRef]

13. Zhang, T.Y.; Zhao, H.M.; Wang, D.Y.; Wang, Q.; Pang, Y.; Deng, N.Q.; Cao, H.W.; Yang, Y.; Ren, T.L. A super flexible and custom-shaped graphene heater. Nanoscale 2017, 9, 14357-14363. [CrossRef]

14. Lin, S.Y.; Zhang, T.Y.; Lu, Q.; Wang, D.Y.; Yang, Y.; Wu, X.M.; Ren, T.L. High-Performance Graphene-Based Flexible Heater for Wearable Applications. RSC Adv. 2017, 7, 27001-27006. [CrossRef]

15. Kim, Y.; Lee, H.R.; Saito, T.; Nishi, Y. Ultra-Thin and High-Response Transparent and Flexible Heater Based on Carbon Nanotube Film. Appl. Phys. Lett. 2017, 110, 153301. [CrossRef]

16. Pyo, K.-H.; Kim, J.-W. Transparent and Mechanically Robust Flexible Heater Based on Compositing of Ag Nanowires and Conductive Polymer. Compos. Sci. Technol. 2016, 133, 7-14. [CrossRef]

17. Zeng, P.; Tian, B.; Tian, Q.; Yao, W.; Li, M.; Wang, H.; Feng, Y.; Liu, L.; Wu, W. Screen-Printed, Low-Cost, and Patterned Flexible Heater Based on Ag Fractal Dendrites for Human Wearable Application. Adv. Mater. Technol. 2019, 4, 1800453. [CrossRef]

18. Park, H.K.; Kim, S.M.; Lee, J.S.; Park, J.H.; Hong, Y.K.; Hong, C.H.; Kim, K.K. Flexible Plane Heater: Graphite and Carbon Nanotube Hybrid Nanocomposite. Synth. Met. 2015, 203, 127-134. [CrossRef] 
19. Młyńczak, M.; Zyliński, M.; Janczak, D.; Jakubowska, M.; Niewiadomski, W.; Cybulski, G. Graphene electrodes for long-term impedance pneumography-A feasibility study. In Proceedings of the European Medical and Biological Engineering Conference, Tampere, Finland, 11-15 June 2017; pp. 514-517.

20. Dybowska-Sarapuk, L.; Janczak, D.; Podsiadly, B.; Jakubowska, M.; Sloma, M. Electrical and Rheological Percolation Threshold of Graphene Pastes for Screen-Printing. Circuit World 2019, 45, 26-30. [CrossRef]

21. Pepłowski, A.; Rathi, S.; Piotrkowski, B.; Ziółkowski, R.; Janczak, D.; Krzemiński, J.; Brosch, M.; Jakubowska, M. Electrochemistry of Graphene Nanoplatelets Printed Electrodes for Cortical Direct Current Stimulation. Front. Neurosci. 2020, 14. [CrossRef]

22. Bourrat, X. Electrically Conductive Grades of Carbon Black: Structure and Properties. Carbon 1993, 31, 287-302. [CrossRef]

23. Gubbels, F.; Jerome, R.; Teyssie, P.; Vanlathem, E.; Deltour, R.; Calderone, A.; Parents, V.; Bredas, J.L. Selective Localization of Carbon Black in Immiscible Polymer Blends: A Useful Tool To Design Electrical Conductive Composites. Macromolecules 1994, 27, 1972-1974. [CrossRef]

24. Duan, L.; Spoerk, M.; Wieme, T.; Cornillie, P.; Xia, H.; Zhang, J.; Cardon, L.; D’hooge, D.R. Designing Formulation Variables of Extrusion-Based Manufacturing of Carbon Black Conductive Polymer Composites for Piezoresistive Sensing. Compos. Sci. Technol. 2019, 171, 78-85. [CrossRef]

25. Phillips, C.; Al-Ahmadi, A.; Potts, S.J.; Claypole, T.; Deganello, D. The Effect of Graphite and Carbon Black Ratios on Conductive Ink Performance. J. Mater. Sci. 2017, 52, 9520-9530. [CrossRef]

26. Sengupta, R.; Bhattacharya, M.; Bandyopadhyay, S.; Bhowmick, A.K. A Review on the Mechanical and Electrical Properties of Graphite and Modified Graphite Reinforced Polymer Composites. Prog. Polym. Sci. 2011, 36, 638-670. [CrossRef]

27. Kalaitzidou, K.; Fukushima, H.; Drzal, L.T. Multifunctional Polypropylene Composites Produced by Incorporation of Exfoliated Graphite Nanoplatelets. Carbon 2007, 45, 1446-1452. [CrossRef]

28. Zheng, W.; Wong, S.C. Electrical Conductivity and Dielectric Properties of PMMA/expanded Graphite Composites. Compos. Sci. Technol. 2003, 63, 225-235. [CrossRef] 